\title{
Improved Reliability of Small Molecule Organic Solar Cells by Double Anode Buffer Layers
}

\author{
Pao-Hsun Huang, ${ }^{1}$ Chien-Jung Huang, ${ }^{1}$ Kan-Lin Chen, ${ }^{2}$ Jhong-Ciao Ke, ${ }^{3}$ \\ Yeong-Her Wang, ${ }^{3}$ and Chih-Chieh Kang ${ }^{4}$ \\ ${ }^{1}$ Department of Applied Physics, National University of Kaohsiung, Kaohsiung 81148, Taiwan \\ ${ }^{2}$ Department of Electronic Engineering, Fortune Institute of Technology, Kaohsiung 83160, Taiwan \\ ${ }^{3}$ Institute of Microelectronics, Department of Electrical Engineering, National Cheng-Kung University, Tainan 70101, Taiwan \\ ${ }^{4}$ Department of Electro-Optical Engineering, Southern Taiwan University of Science and Technology, Tainan 71005, Taiwan
}

Correspondence should be addressed to Chien-Jung Huang; chien@nuk.edu.tw and Kan-Lin Chen; klchen@fotech.edu.tw

Received 16 June 2014; Accepted 3 July 2014; Published 15 July 2014

Academic Editor: Ying-Chung Chen

Copyright (c) 2014 Pao-Hsun Huang et al. This is an open access article distributed under the Creative Commons Attribution License, which permits unrestricted use, distribution, and reproduction in any medium, provided the original work is properly cited.

An optimized hybrid planar heterojunction (PHJ) of small molecule organic solar cells (SM-OSCs) based on copper phthalocyanine $(\mathrm{CuPc})$ as donor and fullerene $\left(\mathrm{C}_{60}\right)$ as acceptor was fabricated, which obviously enhanced the performance of device by sequentially using both $\mathrm{MoO}_{3}$ and pentacene as double anode buffer layers (ABL), also known as hole extraction layer (HEL). A series of the vacuum-deposited $\mathrm{ABL}$, acting as an electron and exciton blocking layer, were examined for their characteristics in SM-OSCs. The performance and reliability were compared between conventional ITO/ABL/CuPc/ $\mathrm{C}_{60} / \mathrm{BCP} / \mathrm{Ag}$ cells and the new ITO/double $\mathrm{ABL} / \mathrm{CuPc} / \mathrm{C}_{60} / \mathrm{BCP} / \mathrm{Ag}$ cells. The effect on the electrical properties of these materials was also investigated to obtain the optimal thickness of ABL. The comparison shows that the modified cell has an enhanced reliability compared to traditional cells. The improvement of lifetime was attributed to the idea of double layers to prevent humidity and oxygen from diffusing into the active layer. We demonstrated that the interfacial extraction layers are necessary to avoid degradation of device. That is to say, in normal temperature and pressure, a new avenue for the device within double buffer layers has exhibited the highest values of open circuit voltage $\left(V_{\mathrm{oc}}\right)$, fill factor $(\mathrm{FF})$, and lifetime in this work compared to monolayer of ABL.

\section{Introduction}

Organic solar cells (OSCs) have strong potential advantages compared with conventional inorganic solar cells, which could expand the range of applications, including low-cost, light-weight, colorful, mechanically flexible, and large-area devices. Now, a milestone in efficiency of OSCs has been achieved in recent years, allowing for $10 \%$ power conversion efficiency (PCE) by tandem structures even significant to $12 \%$ [1], which makes its commercial industrialization very promising. Many works also tend to design the appropriate configuration for carrier generation and transportation to attain high efficiency and stability. At the same time, a lot of organic semiconducting materials have extremely interesting properties in terms of photocurrent generation and reveal very high absorption coefficients in the visible region of the solar spectrum for even $<100 \mathrm{~nm}$ films, making them promising compounds for photovoltaic devices [2]. Copper phthalocyanine $(\mathrm{CuPc})$ was employed as a donor in the first bilayer heterojunction OSC reported in the literature over two decades [3]. Their well-known capability stems from the sensitizer by photo-induced electron transfer to acceptors. It was coupled with the fullerenes $\left(\mathrm{C}_{60}\right.$ or $\left.\mathrm{C}_{70}\right)$ when the photo-induced electron transfer was employed. However, on the contrary, the reliability studies and the scientific explanations of degradation phenomena of OSCs device have not been further researched. Reliability is particularly difficult to discuss because both device parameters and experimental factors would intensively affect the degradation of device, as well as the possibility for interplay among these factors. 
Some groups have tested for reliability of OSCs by applying indium tin oxide (ITO) as an anode, the poly(3, 4-thylenedioxythiophene)-poly(styrenesulfonate) (PEDOT: PSS) or metal oxide $\left(\mathrm{MoO}_{3}, \mathrm{WO}_{3}, \mathrm{~V}_{2} \mathrm{O}_{5}\right)$ as the anode buffer layer $(\mathrm{ABL})$, which is penetrative and collects the holes generated in the active layer, and active donor/acceptor layers with a low work function metal aluminium (Al) as the cathode on top of the cell for electron collection [4-7]. Besides, it was indicated that the degradation of OSCs device is determined by the following three important elements, including photodegradation, ambient degradation $\left(\mathrm{H}_{2} \mathrm{O}\right.$ and $\mathrm{O}_{2}$ ), and thermal degradation of the photoactive organic layer [8-15]. We focus on the impact of ambient degradation because the absorption of water would lead to degradation of device performance, reflecting on series resistance $\left(R_{s}\right)$. To achieve planar heterojunction (PHJ) of small molecule organic solar cells (SM-OSCs) and prevent it from water and oxygen damage, the pentacene layer was introduced between the $\mathrm{MoO}_{3}$ and $\mathrm{CuPc}$ layer which provided improved cell stability and kept the performance of device, owing to material characteristics $[16,17]$. The PEDOT: PSS layer was substituted for $\mathrm{MoO}_{3}$ because of wide energy gap semiconductor with high work function [5-7]. The shortage of organic materials is narrow absorption range in visible region, which leads to the low short-circuit current density $\left(J_{\mathrm{sc}}\right)$. Therefore, to get the highest $J_{\mathrm{sc}}$ for the best performance, the optimization of the device structure is necessary $[18,19]$. In this work, we show an important presence of double ABL to improve the reliability of device and further generally elucidate the impact of the interfacial layers on device lifetime and photovoltaic parameters. In addition, the $J_{\mathrm{sc}}$ variation of device with different ABL material and thicknesses is also investigated in detail.

\section{Experiment}

In this study, the vacuum-deposited OSCs device was fabricated on patterned ITO-glass substrate. The ITO-glass substrates with a sheet resistance of $7 \Omega$ /sq were sequentially cleaned by ultrasonic treatment in acetone, isopropyl alcohol, and deionized water for $5 \mathrm{~min}$ each and finally dried by highpurity nitrogen $\left(\mathrm{N}_{2}\right)$ gas before deposition. The organic materials used in the device as $\mathrm{MoO}_{3}$ (99\%), pentacene (99\%), CuPc (99\%), $\mathrm{C}_{60}$ (99.95\%), and BCP (99\%) were purchased from Sigma-Aldrich which were without further purification. All organic materials were successively deposited onto the substrates by thermal evaporation at a deposition rate of $0.02-0.04 \mathrm{~nm} / \mathrm{s}$ below the pressure of $2.3 \times 10^{-6}$ Torr. The $\mathrm{Al}$ as a cathode was deposited to $100 \mathrm{~nm}$ thickness at a deposition rate of $0.02-0.15 \mathrm{~nm} / \mathrm{s}$ by thermal evaporation through a shadow mask, giving an active area of $6 \mathrm{~mm}^{2}$. And the structure of device was ITO/buffer/CuPc $(20 \mathrm{~nm}) / \mathrm{C}_{60}$ $(30 \mathrm{~nm}) / \mathrm{BCP}(10 \mathrm{~nm}) / \mathrm{Al}(100 \mathrm{~nm})$, where the buffer layers were any or all formation of $\mathrm{MoO}_{3}$. The films thickness and deposition rate were monitored by using an oscillating quartz thickness monitor.

The configurations of OSC device and the energy level diagram in this study are shown in Figure 1. The currentvoltage characteristics were measured with a Keithley 2400

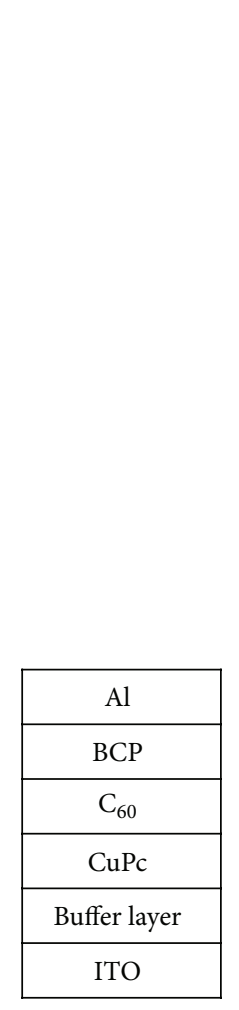

(a)

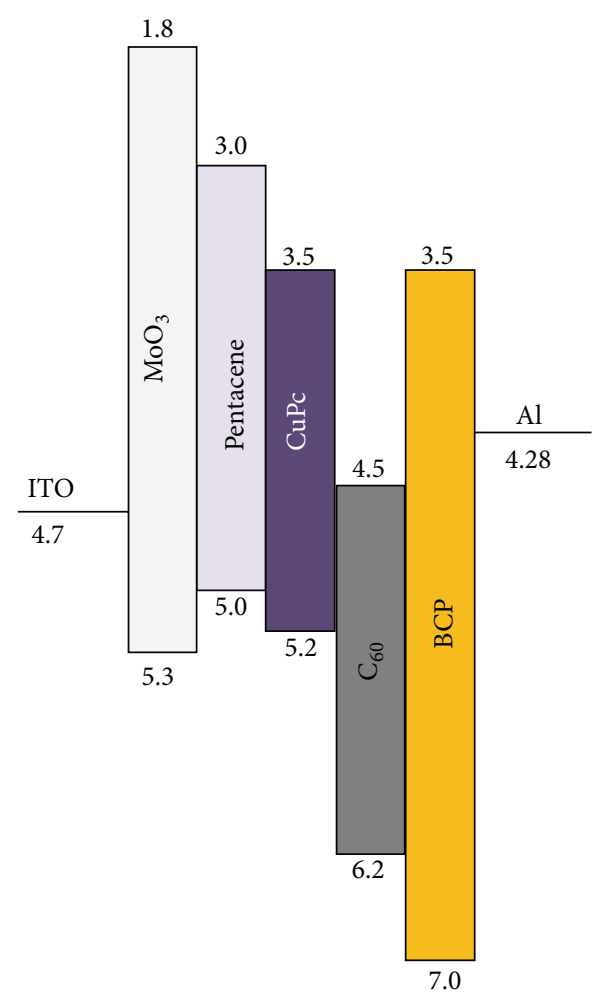

(b)
FIGURE 1: Energy level diagram for the constituent materials in Devices A to D.

source meter, under an illumination of $100 \mathrm{~mW} / \mathrm{cm}^{2}$ with an AM $1.5 \mathrm{G}$ sun simulator. The light intensity was measured using a calibrated Si-solar cell. Devices were further measured by atomic force microscope (AFM) to analyze the surface morphology and by spectrophotometer (Hitachi UV3010, Japan) to gauge the absorption spectrum of device. All measurements were carried out in air with encapsulation.

\section{Results and Discussion}

3.1. OSC Device Characteristics. The PCE of OSC is determined by three important parameters, namely, short circuit density $\left(J_{\mathrm{sc}}\right)$, open circuit voltage $\left(V_{\mathrm{oc}}\right)$, and fill factor $(\mathrm{FF})$. The ITO and Al layers functioned as cathode and anode, respectively. The $\mathrm{CuPc}$ and $\mathrm{C}_{60}$ were the donor and acceptor materials. BCP formed a buffer layer between acceptor and cathode. Four OSCs device structures (Devices A to D) in this work were made up of different hole extracting materials as follows:

Device A: ITO/ $/ \mathrm{MoO}_{3} / \mathrm{CuPc} / \mathrm{C}_{60} / \mathrm{BCP} / \mathrm{Al}$;

Device B: ITO/pentacene/CuPc/C $60 / \mathrm{BCP} / \mathrm{Al}$;

Device C: ITO/ $\mathrm{MoO}_{3} /$ pentacene $/ \mathrm{CuPc} / \mathrm{C}_{60} / \mathrm{BCP} / \mathrm{Al}$;

Device D: ITO/pentacene/ $\mathrm{MoO}_{3} / \mathrm{CuPc} / \mathrm{C}_{60} / \mathrm{BCP} / \mathrm{Al}$.

Figures 1(a) and 1(b) show the energy levels of the OSC and the device structure. The difference between the 


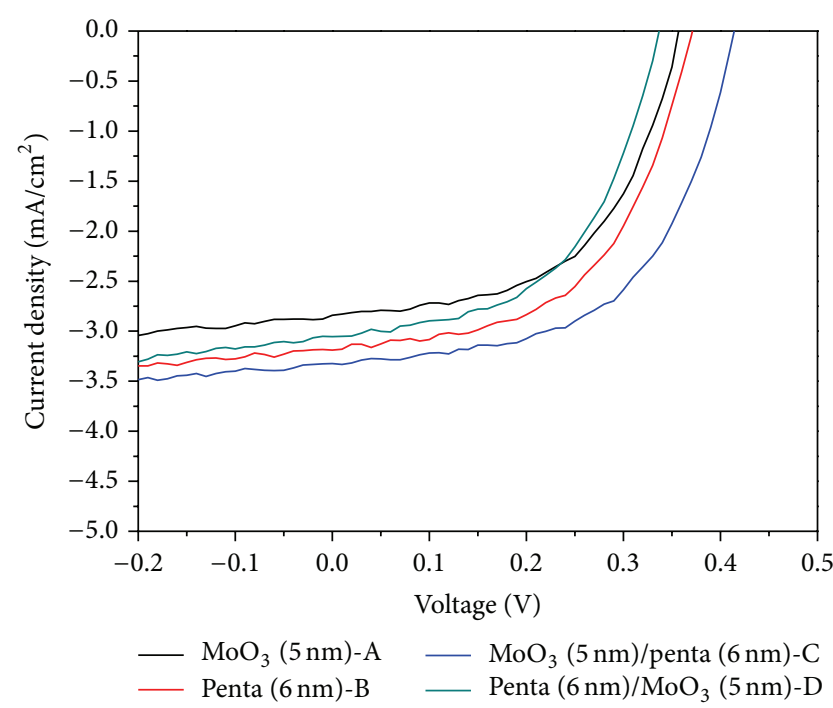

FIgUre 2: $J-V$ curve of cells with differentABL mode of Devices A to $\mathrm{D}$.

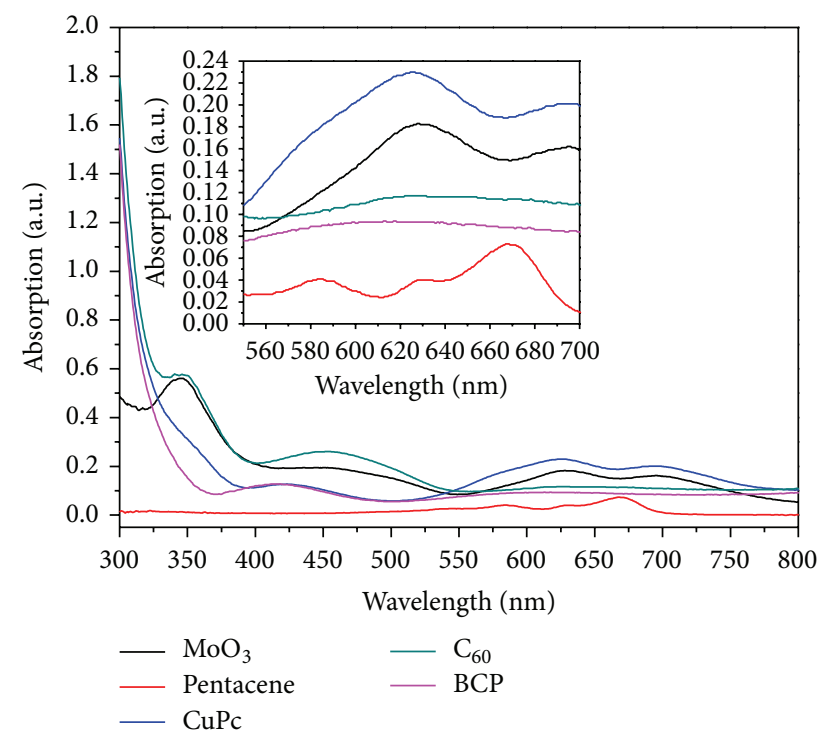

FIGURE 3: The optical absorption spectra of constituent materials in Devices A to D (insert diagram shows the contribution for pentacene layer from $660 \mathrm{~nm}$ to $680 \mathrm{~nm}$ ).

HOMO and LUMO of the organic materials was determined by absorption spectra. Figure 2 shows the current densityvoltage $(J-V)$ characteristics of devices under illumination of 1-sun AM 1.5 G solar radiation. The Devices from A to $\mathrm{D}\left(\mathrm{ITO} /\right.$ buffer layer/ $\left.\mathrm{C}_{60}(30 \mathrm{~nm}) / \mathrm{BCP}(10 \mathrm{~nm}) / \mathrm{Al}(100 \mathrm{~nm})\right)$ consisted of both $\mathrm{MoO}_{3}$ and pentacene materials. Corresponding device parameters, series resistance $\left(R_{s}\right)$, and performance were listed in Tables 1-3. Figure 3 shows the absorption spectra of all devices. The ABL is playing an important role in device because it has not only decreased the effect of non-Ohmic electrodes on device characteristics and revealed properties of the organic heterojunction, but also influenced the ability of carrier transportation in device.
We have completed the optimized parameters of Devices A and $\mathrm{B}$ under the premise of using $\mathrm{MoO}_{3}$ and pentacene as the ABL materials, respectively. First, for Device A using $\mathrm{MoO}_{3}$ material, the best performance was achieved without $\mathrm{MoO}_{3}$ and it was compared to relative articles [20]. It is found that the $\mathrm{MoO}_{3}$ material was not good for basic $\mathrm{CuPc} / \mathrm{C}_{60}$ OSCs using $\mathrm{Al}$ as the cathode, although its advantages of wide energy gap semiconductor with high work function have been reported in many works [5-7]. The $J_{\text {sc }}$ of device decreased from $3.41 \mathrm{~mA} / \mathrm{cm}^{2}$ to $2.84 \mathrm{~mA} / \mathrm{cm}^{2}$ and $V_{\text {oc }}$ from $0.39 \mathrm{~V}$ to $0.36 \mathrm{~V}$ when the $\mathrm{MoO}_{3}$ layer thickness was added from $0 \mathrm{~nm}$ to $5 \mathrm{~nm}$ in Table 2, which is attributed to $R_{s}$ with thicker $\mathrm{MoO}_{3}$ layer. Both of the surface morphology and the $R_{s}$ decreased as the $\mathrm{MoO}_{3}$ layer thickness increased and it also responds to the decreased PCE. Second, for pentacene material, we replaced $\mathrm{MoO}_{3}$ to enhance the device performance. The performance parameters of device with different thicknesses of pentacene layer are summarized in Table 1. According to the downward trend of both $J_{s c}$ and PCE in Table 2, $t$, it was found that $\mathrm{MoO}_{3}$ does not have good reliability for conventional OSCs $\left(\mathrm{CuPc} / \mathrm{C}_{60}\right)$ device although the ITO roughness has been improved. At the same time, we also discovered that the device cannot be enhanced intensively on PCE with the increase of the thickness of pentacene monolayer in Table 1 . To further elucidate the distinction on $\mathrm{MoO}_{3}$ and pentacene, we have focused on the absorption spectrum of used materials in this work. Before measuring these devices, the bare glass substrate is measured as a baseline. The absorptions of $\mathrm{C}_{60}$ contribution (350$520 \mathrm{~nm}$ ) and $\mathrm{CuPc}$ contribution $(550-800 \mathrm{~nm})$ were nearly the same for all devices. The $J_{\text {sc }}$ of device with pentacene layer between ITO anode and CuPc layer slightly increased due to the small decrease of $R_{s}$. It is attributed to the extra absorption of pentacene layer from $660 \mathrm{~nm}$ to $680 \mathrm{~nm}$ in Figure 3. On the other hand, comparing to Device $\mathrm{A}$, the performance of Device B was enhanced from $0.56 \%$ to $0.79 \%$. The reason for improved performance was the material characteristics of pentacene. The pentacene layer built an internal electric field at the interface of pentacene/CuPc that can enhance the hole extraction from CuPc layer to the ITO anode. The physical mechanism of formation of internal electric field within pentacene layer can be elucidated by the energy level diagram of Figure 1. The differences of the highest occupied molecular orbital (HOMO) and lowest unoccupied molecular orbital (LUMO) for pentacene and $\mathrm{CuPc}$ are $0.2 \mathrm{eV}(5.0$ and $5.2 \mathrm{eV}$, resp.) and $0.5 \mathrm{eV}$ (3.0 and $3.5 \mathrm{eV}$, resp.). The difference of energy level is the main cause of the internal electric field, leading to the improved efficiency.

3.2. OSC Reliability. Although the internal electric field was formed at the interface of pentacene/CuPc to strengthen hole extraction [21], the only single ABL for pentacene layer was obviously unhelpful and innocuous to enhance the reliability of Device B. To further enhance the cell performance, we incorporated a pentacene layer between the $\mathrm{MoO}_{3}$ and the $\mathrm{CuPc}$ layer for accomplishing double ABL idea to increase hole extracting ability. Besides, we also completed Devices $\mathrm{C}$ and $\mathrm{D}$ to discuss the sequence problem of both $\mathrm{MoO}_{3}$ 


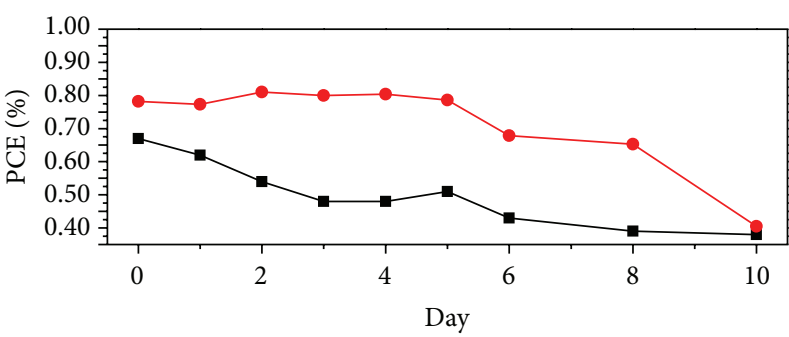

(a)

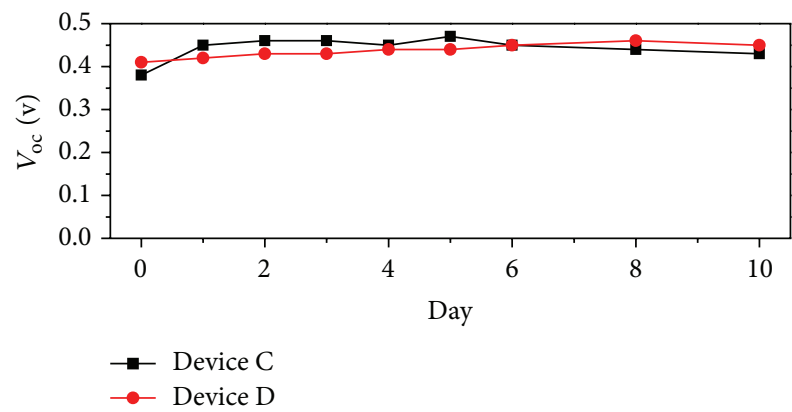

(c)

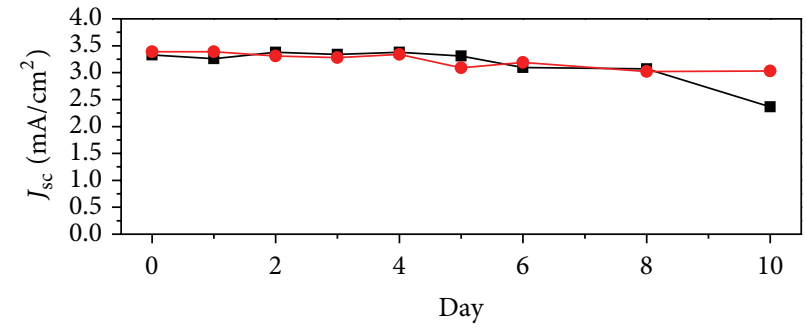

(b)

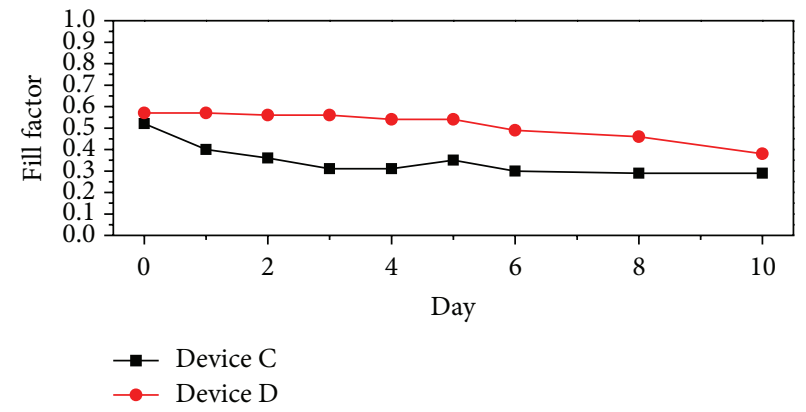

(d)

Figure 4: The parameter, (a) PCE, (b) $J_{\mathrm{sc}}$, (c) $V_{\mathrm{oc}}$, and (d) FF, as a function of time for Devices C and D.

TABLE 1: Photovoltaic performance parameters of ITO/pentacene/ $\mathrm{CuPc} / \mathrm{C}_{60} / \mathrm{BCP} / \mathrm{Al}$ with different pentacene layer thicknesses.

\begin{tabular}{lccccc}
\hline $\begin{array}{l}\text { Pentacene layer } \\
(\mathrm{nm})\end{array}$ & $\begin{array}{c}J_{\text {sc }} \\
\left(\mathrm{mA} / \mathrm{cm}^{2}\right)\end{array}$ & $\begin{array}{c}V_{\text {oc }} \\
(\mathrm{V})\end{array}$ & FF & $\begin{array}{c}R_{S} \text { and } R_{\text {sh }} \\
\left(\Omega \cdot \mathrm{cm}^{2}\right)\end{array}$ & $\begin{array}{c}\text { PCE } \\
(\%)\end{array}$ \\
\hline $0 \mathrm{~nm}$ & 3.41 & 0.39 & 0.54 & $23.63 / 959.73$ & 0.72 \\
$2 \mathrm{~nm}$ & 3.46 & 0.39 & 0.55 & $22.13 / 311.39$ & 0.74 \\
$4 \mathrm{~nm}$ & 3.58 & 0.39 & 0.56 & $20.46 / 637.57$ & 0.79 \\
$6 \mathrm{~nm}$ & 3.39 & 0.38 & 0.52 & $22.21 / 833.93$ & 0.67 \\
\hline
\end{tabular}

TABLE 2: Photovoltaic parameters of ITO/ $\mathrm{MoO}_{3} / \mathrm{CuPc} / \mathrm{C}_{60} / \mathrm{BCP} / \mathrm{Al}$ with different $\mathrm{MoO}_{3}$ layer thicknesses.

\begin{tabular}{lccccc}
\hline $\begin{array}{l}\mathrm{MoO}_{3} \text { layer } \\
(\mathrm{nm})\end{array}$ & $\begin{array}{c}J_{\mathrm{sc}} \\
\left(\mathrm{mA} / \mathrm{cm}^{2}\right)\end{array}$ & $\begin{array}{c}V_{\text {oc }} \\
(\mathrm{V})\end{array}$ & FF & $\begin{array}{c}R_{S} \text { and } R_{\text {sh }} \\
\left(\Omega \cdot \mathrm{cm}^{2}\right)\end{array}$ & $\begin{array}{c}\mathrm{PCE} \\
(\%)\end{array}$ \\
\hline $0 \mathrm{~nm}$ & 3.41 & 0.39 & 0.54 & $23.63 / 959.73$ & 0.72 \\
$3 \mathrm{~nm}$ & 3.12 & 0.37 & 0.55 & $20.67 / 974.63$ & 0.64 \\
$5 \mathrm{~nm}$ & 2.84 & 0.36 & 0.55 & $22.94 / 397.22$ & 0.564 \\
$7 \mathrm{~nm}$ & 3.08 & 0.37 & 0.55 & $21.81 / 1995.76$ & 0.62 \\
\hline
\end{tabular}

and pentacene with optimized thickness in Table 3. In order to obtain reliable and meaningful experimental results for comparison studies, the lifetime data of all devices over 10 days was observed in Figure 4.

Device reliability has a significant status for photoelectric application. The organic-electrode interfaces commonly used in OSCs are inherently unstable and they exhibit photoreduced chemical changes in some studies by using $\mathrm{X}$-ray photoelectron spectroscopy (XPS) measurement [22-24]. The efficiency and reliability are also influenced by the size of the active area [25]. In general, enlarging the active area leads to lower efficiency but higher reliability. This suggested that the degradation is also influenced by air diffused from peripheral edges for our devices. It encourages us to gain a clearer understanding of the basic role of hole extraction layer and to elucidate the phenomena involved in the interfacial degradation mechanism. The $J-V$ characteristics of all devices were measured in the same condition after encapsulation (fixed water and oxygen). The degradation of parameters of Devices C and D was plotted in Figure 4. The preferable reliability of Device $C$ with the $5 \mathrm{~nm} \mathrm{MoO}_{3}$ and $6 \mathrm{~nm}$ pentacene layer was also obtained in Table 3. Without ABL, the lifetime of standard $\mathrm{CuPc} / \mathrm{C}_{60}$ cells is only one day. And the relative parameters were decreased from $3.41 \mathrm{~mA} / \mathrm{cm}^{2}$ to $2.12 \mathrm{~mA} / \mathrm{cm}^{2}$ for $J_{\mathrm{sc}}, 0.54$ to 0.37 for $\mathrm{FF}$, and $0.72 \%$ to $0.36 \%$ for PCE. In Table 3, Device C, using the double ABL $\left(\mathrm{MoO}_{3} /\right.$ pentacene), displays better excellent reliability than that of Device $\mathrm{D}$ (pentacene/ $\mathrm{MoO}_{3}$ ). Device $\mathrm{D}$ has lower $J_{\mathrm{sc}}$ on any thickness of double ABL, comparing to Device $\mathrm{C}$ in Table 3, because the thickness of $\mathrm{MoO}_{3}$ was too thick to transfer hole to anode fluently. Rapid degradation and significant decreases in $J_{\mathrm{sc}}$ and $V_{\mathrm{oc}}$ were also detected. It is clear that the devices are very unstable with single ABL. Within 24 hours, the PCE values of the standard device without ABL reduced to $0.36 \%$ because of a strong decrease in $J_{\mathrm{sc}}, V_{\mathrm{oc}}$, and FF. In contrast, about 5 days later, the PCE of Device B decreases from $0.67 \%$ to $0.51 \%$ and the PCE of Device C still remains at about $0.786 \%$. Although Device C has slightly increased from $0.78 \%$ to $0.81 \%$ after 2 days, it has been proved again that the parameters of cell would rise a little [26]. If device lifetime is defined as the degradation time of PCE from $\mathrm{PCE}_{0}$ to half of it, the lifetime for Devices 
TABLE 3: Photovoltaic performance parameters of $\mathrm{ITO} / \mathrm{MoO}_{3}(X) /$ pentacene $(Y) / \mathrm{CuPc}_{6} \mathrm{C}_{60} / \mathrm{BCP} / \mathrm{Al}$ and $\mathrm{ITO} / \mathrm{pentacene}(Y) / \mathrm{MoO}{ }_{3}(X) /$ $\mathrm{CuPc} / \mathrm{C}_{60} / \mathrm{BCP} / \mathrm{Al}$.

\begin{tabular}{|c|c|c|c|c|c|c|}
\hline $\begin{array}{l}X, Y) \\
(\mathrm{nm}) \\
\end{array}$ & $\begin{array}{c}J_{\mathrm{sc}} \\
\left(\mathrm{mA} / \mathrm{cm}^{2}\right)\end{array}$ & $\begin{array}{l}V_{\text {oc }} \\
(\mathrm{V})\end{array}$ & $\mathrm{FF}$ & $\begin{array}{c}R_{s} \\
\left(\Omega \cdot \mathrm{cm}^{2}\right)\end{array}$ & $\begin{array}{c}R_{\mathrm{sh}} \\
\left(\Omega \cdot \mathrm{cm}^{2}\right)\end{array}$ & PCE (\%) \\
\hline$(5,2)$ & 2.92 & 0.37 & 0.55 & 23.55 & 740.77 & 0.60 \\
\hline$(5,4)$ & 3.28 & 0.38 & 0.55 & 20.76 & 476.46 & 0.69 \\
\hline$(5,6)$ & 3.33 & 0.41 & 0.57 & 23.05 & 3437.92 & 0.78 \\
\hline $\begin{array}{l}Y, X) \\
(\mathrm{nm}) \\
\end{array}$ & $\begin{array}{c}J_{\mathrm{sc}} \\
\left(\mathrm{mA} / \mathrm{cm}^{2}\right)\end{array}$ & $\begin{array}{l}V_{\mathrm{oc}} \\
(\mathrm{V})\end{array}$ & $\mathrm{FF}$ & $\begin{array}{c}R_{s} \\
\left(\Omega \cdot \mathrm{cm}^{2}\right)\end{array}$ & $\begin{array}{c}R_{\mathrm{sh}} \\
\left(\Omega \cdot \mathrm{cm}^{2}\right)\end{array}$ & PCE (\%) \\
\hline$(2,5)$ & 2.85 & 0.34 & 0.54 & 22.42 & 1659.30 & 0.52 \\
\hline$(4,5)$ & 2.97 & 0.33 & 0.54 & 24.25 & 1090.37 & 0.53 \\
\hline$(6,5)$ & 3.06 & 0.34 & 0.53 & 22.17 & 10195.64 & 0.55 \\
\hline$(8,5)$ & 2.67 & 0.34 & 0.53 & 26.29 & 409.95 & 0.48 \\
\hline
\end{tabular}

A to $\mathrm{D}$ can be estimated to be 3 days, 8 days, 10 days, and less than 3 hours, respectively. It is remarkable that the reliability of device of OSCs based on $\mathrm{CuPc} / \mathrm{C}_{60}$ can be ameliorated from 1 day to 10 days by using the scarce double anode buffer layer. The reason may be attributed to the pentacene layer that can separate moisture from ITO anode and the $\mathrm{MoO}_{3}$ layer can protect organic material from oxidized reaction. The holes can cross $\mathrm{MoO}_{3}$ more smoothly by multiple tunneling steps between the gap states introduced by oxygen vacancies [27]. At the same time, the difference of energy level can also form the internal electric field at the interface of pentacene/ $\mathrm{CuPc}$ [21]. It could become another reason why the reliability of Device $C$ is better than that of $\mathrm{D}$. Device $\mathrm{D}$ is a good idea because it has matched the energy level to transport carriers for each other. However, the performance of Device D has not only poor efficiency but weak reliability with different pentacene thicknesses in Table 3. So, the advantage of small molecule OSCs based on $\mathrm{CuPc} / \mathrm{C}_{60}$ was accomplished by depositing the double $\mathrm{ABL}, \mathrm{MoO}_{3}$, and pentacene layer on the ITO-glass substrate sequentially, resulting in the improved device lifetime from 1 to 10 days.

\section{Conclusion}

In this work, we have observed the effect of each and double $\mathrm{ABL}$ on OSCs, which is based on $\mathrm{CuPc} / \mathrm{C}_{60}$ structure, by using $\mathrm{MoO}_{3}$ and pentacene material. The performance of devices with different ABL thicknesses has been investigated. The excellent reliability and best performance of device were achieved simultaneously at $5 \mathrm{~nm} \mathrm{MoO}_{3}$ and $6 \mathrm{~nm}$ pentacene, which are attributed to reaching the water and oxygen resistance property to maintain the carrier collection efficiency in device. And the device lifetime extends to 10 days. Besides, gaining the highest $V_{\text {oc }}$ of device not only needs the deepest HOMO level of donor but also needs the highest work function of anode. The $V_{\text {oc }}$ of device by using ABL is better than that of device using alone layer or without it. As a result, the $V_{\mathrm{oc}}$ is greatly improved from $0.36 \mathrm{~V}$ to $0.41 \mathrm{~V}$ by inserting the $\mathrm{MoO}_{3}$ and pentacene layer sequentially between the ITO and CuPc layer, leading to a steady state in efficiency of device over 10 days. It is thus hinted that the presence of electrode buffer layer would be important in reliability and stability of OSCs because of the movement of generated exciton on organic-electrode interface.

\section{Conflict of Interests}

The authors declare that there is no conflict of interests regarding the publication of this paper.

\section{Acknowledgment}

This work was partially supported by the National Science Council of the Republic of China under Contract no. NSC 102-2221-E-390-019-MY2.

\section{References}

[1] J. You, L. Dou, K. Yoshimura et al., "A polymer tandem solar cell with $10.6 \%$ power conversion efficiency," Nature Communications, vol. 4, no. 1446, pp. 1-10, 2013.

[2] C. Deibel, V. Dyakonov, and C. J. Brabec, "Organic bulkheterojunction solar cells," IEEE Journal on Selected Topics in Quantum Electronics, vol. 16, no. 6, pp. 1517-1527, 2010.

[3] C. W. Tang, "Two-layer organic photovoltaic cell," Applied Physics Letters, vol. 48, no. 2, pp. 183-185, 1986.

[4] N. Li, B. E. Lassiter, R. R. Lunt, G. Wei, and S. R. Forrest, "Open circuit voltage enhancement due to reduced dark current in small molecule photovoltaic cells," Applied Physics Letters, vol. 94, no. 2, Article ID 023307, 3 pages, 2009.

[5] D. Y. Kim, G. Sarasqueta, and F. So, "SnPc: $\mathrm{C}_{60}$ bulk heterojunction organic photovoltaic cells with $\mathrm{MoO}_{3}$ interlayer," Solar Energy Materials and Solar Cells, vol. 93, no. 8, pp. 1452-1456, 2009.

[6] X. Tong, B. E. Lassiter, and S. R. Forrest, "Inverted organic photovoltaic cells with high open-circuit voltage," Organic Electronics: Physics, Materials, Applications, vol. 11, no. 4, pp. 705-709, 2010.

[7] L. Cattin, F. Dahou, Y. Lare et al., "MoO3 surface passivation of the transparent anode in organic solar cells using ultrathin films," Journal of Applied Physics, vol. 105, no. 3, Article ID 034507, 7 pages, 2009.

[8] M. Hermenau, M. Riede, K. Leo, S. A. Gevorgyan, F. C. Krebs, and K. Norrman, "Water and oxygen induced degradation of 
small molecule organic solar cells," Solar Energy Materials and Solar Cells, vol. 95, no. 5, pp. 1268-1277, 2011.

[9] M. Jørgensen, K. Norrman, and F. C. Krebs, "Stability/ degradation of polymer solar cells," Solar Energy Materials and Solar Cells, vol. 92, no. 7, pp. 686-714, 2008.

[10] B. Paci, A. Generosi, V. R. Albertini et al., "Controlling photoinduced degradation in plastic photovoltaic cells: a time-resolved energy dispersive x-ray reflectometry study," Applied Physics Letters, vol. 89, no. 4, Article ID 043507, 3 pages, 2006.

[11] M. Seeland, R. Rsch, and H. Hoppe, "Luminescence imaging of polymer solar cells: Visualization of progressing degradation," Journal of Applied Physics, vol. 109, no. 6, Article ID 064513, 2011.

[12] F. C. Krebs and K. Norrman, "Analysis of the failure mechanism for a stable organic photovoltaic during 10,000 h of testing," Progress in Photovoltaics: Research and Applications, vol. 15, no. 8, pp. 697-712, 2007.

[13] S. Bertho, G. Janssen, T. J. Cleij et al., "Effect of temperature on the morphological and photovoltaic stability of bulk heterojunction polymer: fullerene solar cells," Solar Energy Materials and Solar Cells, vol. 92, no. 7, pp. 753-760, 2008.

[14] S. Bertho, I. Haeldermans, A. Swinnen et al., "Influence of thermal ageing on the stability of polymer bulk heterojunction solar cells," Solar Energy Materials and Solar Cells, vol. 91, no. 5, pp. 385-389, 2007.

[15] D. E. Motaung, G. F. Malgas, and C. J. Arendse, "Insights into the stability and thermal degradation of P3HT: $\mathrm{C}_{60}$ blended films for solar cell applications," Journal of Materials Science, vol. 46, no. 14, pp. 4942-4952, 2011.

[16] J. Yu, J. Huang, L. Zhang, and Y. Jiang, "Energy losing rate and open-circuit voltage analysis of organic solar cells based on detailed photocurrent simulation," Journal of Applied Physics, vol. 106, no. 6, Article ID 063103, 6 pages, 2009.

[17] Y.-H. Lou, M.-F. Xu, Z. Wang, S. Naka, H. Okada, and L.S. Liao, "Dual roles of $\mathrm{MoO}_{3}$-doped pentacene thin films as hole-extraction and multicharge-separation functions in pentacene $/ \mathrm{C}_{60}$ heterojunction organic solar cells," Applied Physics Letters, vol. 102, no. 11, Article ID 113305, 4 pages, 2013.

[18] L. Chen, Y. Tang, X. Fan et al., "Improvement of the efficiency of $\mathrm{CuPc} / \mathrm{C}_{60}$-based photovoltaic cells using a multistepped structure," Organic Electronics, vol. 10, no. 4, pp. 724-728, 2009.

[19] S. M. Schultes, P. Sullivan, S. Heutz, B. M. Sanderson, and T. S. Jones, "The role of molecular architecture and layer composition on the properties and performance of CuPc-C60 photovoltaic devices," Materials Science and Engineering $C$, vol. 25, no. 5-8, pp. 858-865, 2005.

[20] G. Cao, L. Li, M. Guan, J. Zhao, Y. Li, and Y. Zeng, "Stable organic solar cells employing $\mathrm{MoO}_{3}$-doped copper phthalocyanine as buffer layer," Applied Surface Science, vol. 257, no. 22, pp. 9382-9385, 2011.

[21] C. J. Huang, J. C. Ke, W. R. Chen, T. H. Meen, and C. Yang, "Improved the efficiency of small molecule organic solar cell by double anode buffer layers," Solar Energy Materials and Solar Cells, vol. 95, no. 12, pp. 3460-3464, 2011.

[22] G. Williams, Q. Wang, and H. Aziz, "The photo-stability of polymer solar cells: contact photo-degradation and the benefits of interfacial layers," Advanced Functional Materials, vol. 23, no. 18, pp. 2239-2247, 2013.

[23] Q. Wang, G. Williams, and H. Aziz, "Photo-degradation of the indium tin oxide (ITO)/organic interface in organic optoelectronic devices and a new outlook on the role of ITO surface treatments and interfacial layers in improving device stability," Organic Electronics, vol. 13, no. 10, pp. 2075-2082, 2012.
[24] Q. Wang, G. Williams, T. Tsui, and H. Aziz, "Photochemical deterioration of the organic/metal contacts in organic optoelectronic devices," Journal of Applied Physics, vol. 112, no. 6, Article ID 064502, 7 pages, 2012.

[25] M. Wang, F. Xie, J. Du et al., "Degradation mechanism of organic solar cells with aluminum cathode," Solar Energy Materials and Solar Cells, vol. 95, no. 12, pp. 3303-3310, 2011.

[26] S. S. Ardestani, R. Ajeian, M. N. Badrabadi, and M. Tavakkoli, "Improvement in stability of bilayer organic solar cells using an ultra-thin Au layer," Solar Energy Materials and Solar Cells, vol. 111, pp. 107-111, 2013.

[27] L. Cattin, F. Dahou, Y. Lare et al., " $\mathrm{MoO}_{3}$ surface passivation of the transparent anode in organic solar cells using ultrathin films," Journal of Applied Physics, vol. 105, no. 3, Article ID 034507, 7 pages, 2009. 

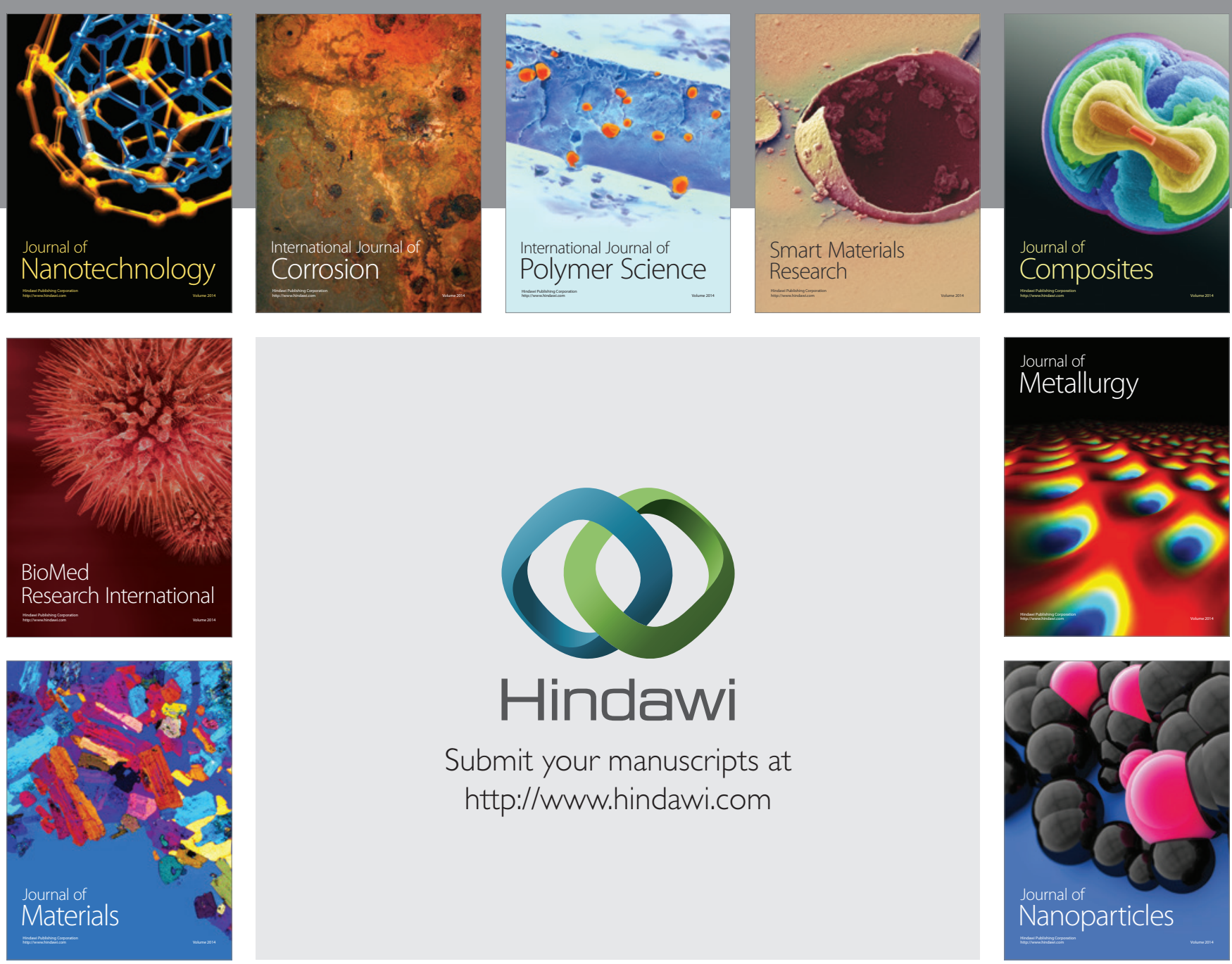

Submit your manuscripts at http://www.hindawi.com
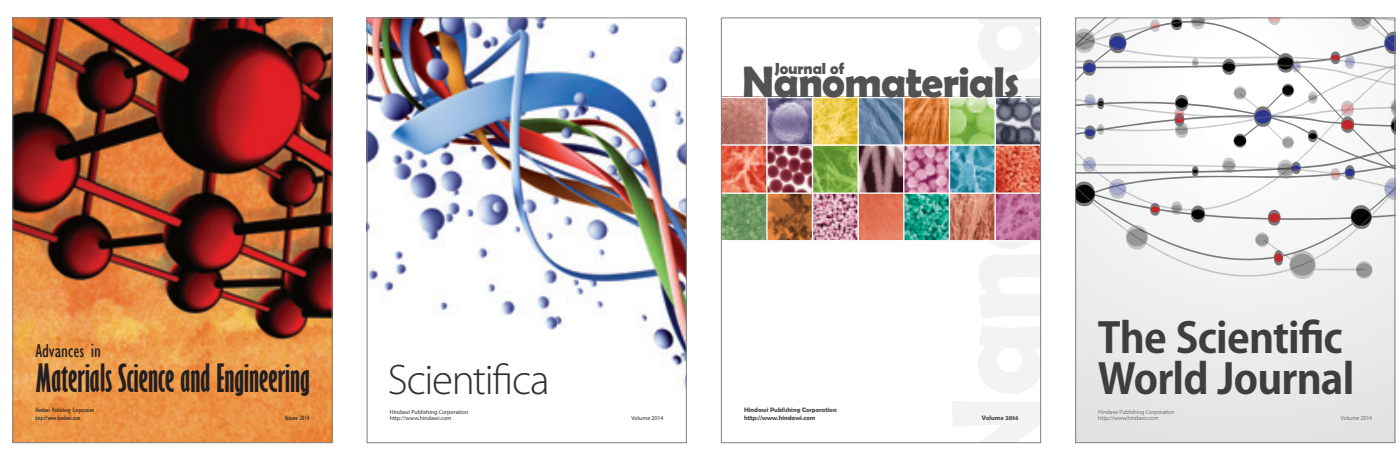

\section{The Scientific World Journal}
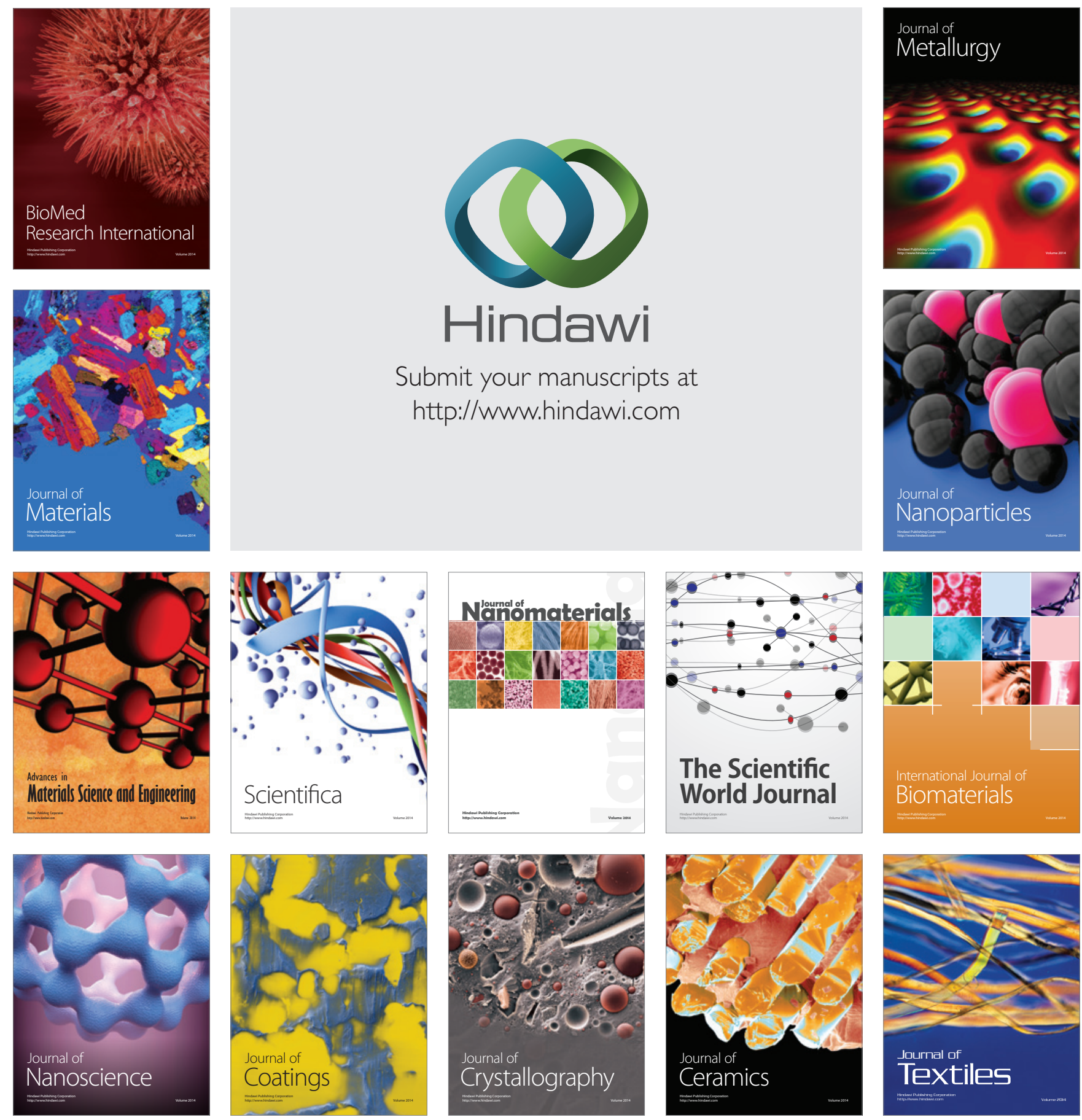